\title{
Introduction to the BASIN Special Issue: State of art, past present a view to the future
}

\author{
St John M.A. ${ }^{1}$, Barange Manuel ${ }^{2}$, Benway Heather ${ }^{3}$, Flynn Kevin J. ${ }^{4}$, Holt Jason ${ }^{5}$, Merino Gorka ${ }^{6}$, \\ Martin A. ${ }^{7}$, Mitra Aditee ${ }^{4}$, Melle Webjorn ${ }^{8}$, Sanders R. ${ }^{7}$, Trenkel Verena ${ }^{9}$, Grigorov I. ${ }^{1}$, Hoffman
}

\footnotetext{
${ }^{1}$ National Institute of Aquatic Resources, Technical University of Denmark, Jaegersborg Alle 1, 2920 Charlottenlund, Denmark

${ }^{2}$ Plymouth Marine Laboratory, Prospect Place, West Hoe, Plymouth, Devon PL1 3DH, UK

${ }^{3}$ Ocean Carbon \& Biogeochemistry Program, Woods Hole Oceanographic Institution, MS \#25, 266 Woods Hole Rd., Woods Hole, MA 02543, USA

${ }^{4}$ Centre for Sustainable Aquatic Research (CSAR), Swansea University, Swansea SA2 8PP, UK

${ }^{5}$ National Oceanography Centre Joseph Proudman Building, 6 Brownlow Street, Liverpool L3 5DA, UK

${ }_{7}^{6}$ AZTI-Tecnalia, Herrera Kaia, Portualdea, z/g, Pasaia (Gipuzkoa) 20110, Spain

${ }^{7}$ National Oceanography Centre, European Way, Southampton SO14 3ZH, UK

${ }^{8}$ Institute of Marine Research, P.O. Box 1870 Nordnes, 5817 Bergen, Norway

${ }^{9}$ IFREMER. Rue de l'lle d'Yeu, BP 21105, 44311 Nantes Cedex 03, France

${ }^{10}$ Old Dominion University, 4111 Monarch Way Norfolk, VA 23508, USA
}

\section{Introduction}

Marine ecosystems are complex networks of organisms interacting either directly or indirectly while under the influence of the physical and chemical properties of the medium they inhabit. The interplay between these biological agents and their abiotic environment results in complex non-linear responses to individual and multiple stressors, influenced by feedbacks between these organisms and their environment. These ecosystems provide key services that benefit humanity such as food provisioning via the transfer of energy to exploited fish populations or climate regulation via the sinking, subsequent mineralization and ultimately storage of carbon in the ocean interior. 
These key characteristics or emergent features of marine ecosystems are subject to rapid change (e.g. regime shifts; Alheit et al. 2005; Scheffer et al. 2009), with outcomes that are largely unpredictable in a deterministic sense.

The North Atlantic Ocean is host to a number of such systems which are collectively being influenced by the unique physical and chemical features of this ocean basin, such as the Atlantic Meridional Overturning Circulation (AMOC), the basin's ventilation with the Arctic Ocean, the dynamics of heat transport via the Gulf Stream and the formation of deep water at high latitudes. These features drive the solubility and biological pumps and support the production and environments that results in large exploited fish stocks. Our knowledge of its functioning as a coupled system, and in particular how it will respond to change, is still limited despite the scientific effort exerted over more than 100 years. This is due in part to the difficulty of providing synoptic overviews of a vast area, and to the fact that most fieldwork provides only snapshots of the complex physical, chemical and biological processes and their interactions. These constraints have in the past limited the development of a mechanistic understanding of the basin as a whole, and thus of the services it provides.

An overarching property of North Atlantic ecosystems, in both shelf seas and the open ocean, is that a common atmospheric forcing influences them. However, our mechanistic understanding of how this forcing affects the biochemical, biological and ecological processes of the system, and how these will be affected by climate change, is in its infancy. There is a pressing requirement to better understand the role of basin scale processes within the North Atlantic, as well as to how to downscale from the basin scale to the local scales, where most of the economically important processes take place.

The purpose of this special issue is to assess the current status of knowledge on the functioning of North Atlantic marine ecosystems and the services these systems provide, based on preliminary research conducted by the European FP7 Integrated Project Euro-BASIN. This research, as well as recent work outside the project, is then used to suggest priority areas for future research to progress in our understanding of the links between biogeochemical fluxes and ecosystem services in the North Atlantic. 


\section{History of the North Atlantic BASIN Initiative}

The starting point for EURO-BASIN were discussions at the EurOcean conference in Hamburg in 2000, focusing on perspectives for European and North American research cooperation in the North Atlantic. This conference resulted in a memorandum of understanding, signed between the USA National Science Foundation (NSF) and the European Commission (EC), agreeing to support collaborative research in the North Atlantic. However, it was not until 2005 when funds from the USA NSF and the European network of excellence EURO-OCEANS allowed for European, USA and Canadian scientists to meet in Reykjavik, Iceland (Wiebe et al. 2009), to start the process leading to the development of an International North Atlantic Basin scale Science Plan. Subsequently, support for the BASIN community to hold three meetings in 2007-2008 was obtained from the US NSF and a EU 6th Framework Specific Support Action (SSA) BASIN. These meetings, which built upon the issues identified in Reykjavik, were held in Hamburg (Germany), Chapel Hill (USA), and Amsterdam (the Netherlands). The outcome of these meetings was the International BASIN Science plan, published as a GLOBEC international report (Wiebe et al. 2009). Alas, while the science needs were collectively agreed upon, the difficulty of funding coordinating research (both in time and in concept) from both sides of the Atlantic was not easily resolved. Yet, the European Commission moved forward with a call for proposals, which targeted some of the issues outlined in the International BASIN Science Plan. Specifically, the call was focused scientifically "on the need to improve the understanding of the variability, potential impacts, and feedbacks of global change and anthropogenic forcing on the structure, function and dynamics of the ecosystems of the North Atlantic Ocean and associated shelf seas and on their capacity to provide services. The successful project needed to provide new data, analyses and the models necessary to:

(1) Understand and simulate the population structure and dynamics of broadly distributed, and biogeochemically and trophically important plankton and fish species, to resolve the impacts of climate variability on marine ecosystems and the feedbacks to the earth system; and

(2) Develop understanding and strategies that would contribute to improving and advancing ocean management (ecosystem approach).

In response to this call, the successful EURO-BASIN consortium was formed (European Basin Scale Analyses and Synthesis), using as its starting point the BASIN International Science plan. While a 
similar funding mechanism was not forthcoming from the North American side, North American scientists were able to take advantage of opportunities to participate in EURO-BASIN cruise programs, meetings and to publish joint articles (e.g. this special issue).

\section{Objectives and Goals of EURO-BASIN}

The overarching objectives of EURO-BASIN are encapsulated in the call described above. In order to achieve these objectives, and using the BASIN international science plan as a guideline, the program was geared to:

1) Resolve the influence of climate variability and change, for example changes in temperature, stratification, transport and acidification, on the seasonal cycle of primary productivity, trophic interactions, and fluxes of carbon from the pelagic to the to the deep ocean.

2) Identify how life history strategies and vital rates and limits of key ecosystem and biogeochemical players contribute to the observed population dynamics, community structure, and biogeography.

3) Assess how the removal of exploited species influences marine ecosystems and the fluxes of carbon?

4) Improve the science basis for ecosystem based management targets outlined in the EC Common Fisheries Policy (CFP), the Marine Strategy Framework Directive (MSFD), the European Strategy for Marine and Maritime Research and the Integrated Maritime Policy for the European Union.

The project funded a consortium of 24 institutions from 9 European countries to conduct coordinated research for the period 2010-2014. This volume summarizes some of the preliminary results of the programme to date as well as the state of the art in the different research areas.

\section{The EURO-BASIN special issue}

One of the goals of EURO-BASIN as outlined above was to understand the role of ecosystem restructuring on the efficiency of the biological carbon pump (BCP). As a first step, developing reliable estimates of the magnitude of the North Atlantic biological carbon pump are necessary. To this end Sanders et al. 2014 provided a synthesis of the estimates of strength of BCP in the North

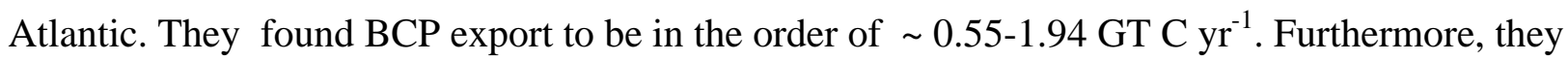




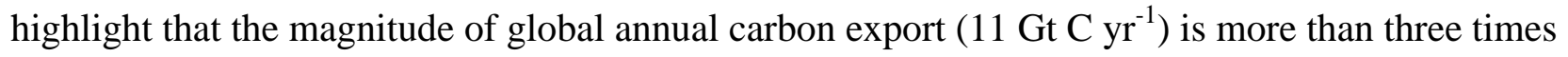
larger than the annual accumulation of $\mathrm{CO}_{2}$ in the atmosphere due to anthropogenic processes $(3.2 \mathrm{Gt}$

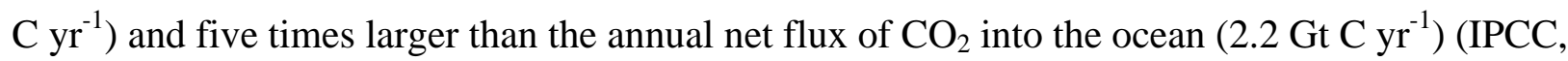
2007). Small changes in primary production and/or its fate can significantly affect the magnitude of the $\mathrm{BCP}$, and through this, ocean- atmosphere $\mathrm{CO}_{2}$ partitioning (Rost et al. 2008). Here, Giering et al. (2014) confirmed that zooplankton play a critical role in the BCP, by repackaging organic carbon produced via photosynthesis into faecal pellets thereby the sinking speed of organic material from the surface layer (Turner, 2002). However, in contrast other coprophagic copepod species consume and break up sinking particles, respiring part of this material at different layers of the water column and decreasing flux rates. In a number of papers in this issue the importance of the role of zooplankton is a recurrent theme, including the consequences of shifts in Calanus biogeography (Wassmann, 1998) and the role of vertical migration (Bianchi et al. 2013). In contrast to Calanus, small copepod species do not perform extensive dial vertical migrations, their grazing impact on the phytoplankton community can still exceed that of Calanus spp. (Morales et al. 1991) thus they can maintain significant amounts of carbon nearer the surface (Kiørboe 2000, Koski et al. 2005).Sanders et al. (this issue) highlight this issue stating that the fraction of primary production exported is strongly dependent on the match or mismatch of primary producers and consumers and on the capacity of the pelagic microbial community to remineralise particulate organic matter (Wassmann, 1998). For example, in extreme cases as much as $70 \%$ of primary production has been observed to leave the euphotic zone through the sinking of individual cells and particles (Lignell et al. 1993). Typically, however, only $10-30 \%$ of material produced via primary production is expected to sink below $100 \mathrm{~m}$ (Wassmann et al. 2003; Thomalla et al. 2008 Buesseler and Boyd, 2009), with ultimately only 1\% of surface primary production is thought to be sequestered in the deep ocean (Ducklow et al. 2001; Poulton et al. 2010). Clearly from these findings a restructuring of the lower trophic levels as a result of changes in ecosystem functioning and species dominance, has the potential to influence the efficiency of the North Atlantic biological carbon pump and as a result global climate..

In order to summarize and extend our understanding of the zooplankton community in the North Atlantic Melle et al. (this issue), provide a new pan-Atlantic compilation and analysis of data on $C$. finmarchicus, a key copepod species in this system. Their article summarizes and extends the state of the art with respect to abundance, demography, dormancy, egg production and mortality in relation to basin-scale patterns of temperature, phytoplankton biomass, circulation and other environmental 
characteristics. A number of features emerge from this analysis. These include the role of the contrasting regimes in the eastern and western Atlantic for the populations of this key ecosystem player. For example, diapause duration, timing of recruitment relative to the spring bloom as well as individual size, survival and mortality all differ between the eastern and western Atlantic systems. Melle et al. (this issue) highlights that new understanding of habitat suitability, life history strategy and physical-biological coupling of $C$. finmarchicus requires further study in order to adequately reparameterize life history processes of this species. They note that the Continuous Plankton Recorder (CPR) data in the basin does not include the species population centers in the Norwegian Sea or the Labrador Sea, where the highest population densities are located, and that locations not closely connected to these deep basins had lower population densities. This information suggests that our present understanding of the processes governing the dynamics of this species needs further examination. Finally, this article highlights questions about the generality of parameterization of growth, reproduction and diapause timing across the North Atlantic, which are particularly critical for modeling studies.

Mitra et al. (this issue) further extended our understanding of the physiology of zooplankton for modeling their vital rates. These authors conducted a comprehensive review of our understanding of zooplankton communities from experimental (laboratory and field) as well as modeling perspectives, in order to update zooplankton parameter estimates. They provide an extensive tabulated summary of the current status of knowledge for the ecophysiological vital rates of the different zooplankton groups, from protists to fish larvae. From this review is clear that experimental investigations typically concentrate on very few groups of zooplankton, of which the female copepod is the exemplar (Cripps et al. 2014). This traditional focus needs to advance to encompass recent views, which identify the increasing role of mixotrophic protists in plankton ecology (Flynn et al. 2013; Mitra et al. 2014). The authors highlight the need to better understand how the different oceanic trophic components interact. They posit that integrative end-to-end ecosystem studies often employ either a bottom-up approach centering on primary production (Vichi et al. 2007a,b) or a top-down approach with a focus on fish productivity (Trenkel et al, this issue and references therein).Typically zooplankton communities (protists and metazoans), which form the vital link between the oceanic primary producers and the higher trophic levels take a back seat or are essentially ignored (Mitra and Davis 2010). Within ecosystem modeling studies, when zooplankton are represented they are usually incorporated in an extremely simplistic fashion (Anderson and Mitra, 2010; Allen and Polimene, 
2011). Performing a dynamic risk assessment, Mitra et al. (this issue) demonstrate the sensitivity of simulated trophic dynamics to small changes in parameter values describing these vital rates and thus emphasizing the importance of using appropriate zooplankton descriptors. The review specifically identifies a list of issues, which need to be addressed via integrated experimental and modeling studies such as the impact of food selectivity and kinetics of prey consumption on different agestages, dynamic data series of zooplankton predator and prey interactions under varied $\mathrm{pH}$ and temperature regimes.

One of the major structuring factors of marine ecosystems is the predatory influence exerted by marine fish stocks either by their presence or absence in the system. Trenkel et al. (this issue) review the current knowledge on the ecology of major pelagic fish stocks in the North Atlantic basin focusing on their role in the food web and the environmental factors influencing their population and spatial dynamics. They examine the major stocks, in particular those assumed to have the potential to exert top-down controls on lower trophic levels. The review focuses on the links between life history processes and the environment, horizontal and vertical distribution, spatial structure and trophic role. From this the authors highlight modeling needs and briefly evaluate the suitability of existing ecosystem models. The authors identify that oceanographic features such as the North Atlantic subpolar gyre play an important role in determining spatial distributions with variations in the gyre influencing stock size. Given the large biomasses of especially the smaller species considered here, these stocks can exert significant top-down pressures on the food web and are important in supporting higher trophic levels. This review als o shows that there are generally few differences in distribution patterns and life history parameters between stocks of the same species of small pelagics on either side of the North Atlantic, though migration distances and the overall spatial distributions are much larger on the eastern side. In contrast, there are bigger differences among species. For example, in the NE Atlantic two small pelagic species, mackerel and blue whiting, utilize the same area for spawning although with little temporal overlap. Critically for understanding the functioning of the trophic cascade, is the role of small and large pelagic species. The former can be strong competitors for food exerting both top-down and bottom-up control, while the later seem to occupy narrower trophic niches and if they exert control on food webs, it is limited in space and time.

Coupled hydrodynamic ecosystem models (Holt et al this issue) provide a vital tool to explore the interactions between biogeochemistry and ecosystems and the wider Earth System, given their 
capability to investigate multiple connected components of the system and the sensitivity to multiple drivers, including potential future conditions. Holt et al., (this issue) review the approaches to the modeling of marine ecosystems with a focus on the North Atlantic Ocean and its adjacent shelf seas. The review aims to highlight the challenges these models face and suggest ways forward. The paper considers the state-of-the-art in simulating oceans and shelf sea physics, planktonic and higher trophic level ecosystems, and looks towards building an integrative approach with these existing tools. They identify that different approaches have evolved historically between shelf and open ocean, however many of the previous obstacles to harmonization may no longer be present.

Several themes emerge from this review, notably the key role horizontal resolution plays in defining the physical environment of a basin scale model. Also the need for multiple model views of the ecosystem is evident, since no single model system provides a holistic capability. These views need to encompass different aspects of the food-web, biogeochemical cycles of varying complexity, and both Eulerian and Lagrangian representations of the dynamics. Inter-operability and inter-comparison between these approaches then becomes a particular challenge. Singly and in combination, these tools allow us to assess the emergent properties of ecosystems, and create metrics for the prediction of future states and to contribute to the assessment and implementation of an ecosystem approach for the management of exploited resources.

The North Atlantic ecosystem provides a number of valuable services to society including the production of food through commercial fisheries. Merino et al. (this issue) examine the economic importance of fisheries within the basin and estimate the cost of ineffective fisheries management in recent decades, defining 'ineffective' as the deviation from the potential maximum economic profit (Arnason et al. 2009). In order to do so they utilized fisheries production and economic indicators over the last few decades to quantify the expected maximum economic yield of North Atlantic fisheries. The model used is an aggregated surplus production model, which has ecological limitations but is able to produce robust estimates of multispecies environments and provides a tool to generate macro scale assessments in combination with economic ancillary information. The authors confirm that the catch and value of North Atlantic fisheries have declined significantly in the last decade, in part due to the restriction of catches through management measures. They estimate that the economic opportunity lost through the inefficient management of North Atlantic fisheries in 2010 could be as large as $\mathrm{B} € 12.2$, compared to current estimated profits of $\mathrm{B} € 0.63$. They conclude 
that in order to maximize the profits derived from North Atlantic fisheries, total fish biomass would have to be rebuilt to levels approximating $108 \mathrm{Mt}$ (2.4 times more than present), and would require a reduction of current total fishing effort by ca. 53\%. This study provides economic justification for maintaining or restoring fish stocks to above MSY biomass levels, by significantly reducing fishing effort.

\section{Where to from EURO-BASIN?}

Future research in the North Atlantic can be viewed on two levels, these being gaps in basic scientific understanding and overarching issues facing the community. In all articles in this special issue, the authors identify areas for future research, which primarily fall into the former category and as such identify key issues to be imbedded in larger scale programs focused on overarching issues. However the overarching questions, which face us are of a different magnitude. A magnitude which requires, given the interconnected nature of the system a multinational collaboration including participating nations on both sides of the Atlantic in order to capture the dynamics of the services and features of the North Atlantic system. Some of these questions which have been identified via discussions with the international community are as follows;

What are the critical dynamical processes and feedbacks driving variability and change in the coupled atmosphere-ocean-cryosphere North AtlanticArctic climate system?

How will biogeochemistry of shelf and open ocean waters of the North Atlantic and Arctic respond to climate variability and increasing human pressures?

How will marine ecosystem structure and function (including feedbacks) respond to environmental change in climate, ocean physics, biogeochemistry, and human pressures (multiple stressors)? 
What are the interactions between humans and a changing North AtlanticArctic marine system, considering perspectives of human health and well being and informing sustainable management practices?

These questions clearly reflect the complex coupled nature of the system and the need to employ a systems approach in addressing them. Hence a multi-national, multidisciplinary effort involving riparian states and expertise in research disciplines from climate to socioeconomics is required to develop the understanding and capacities necessary to manage the resources of this system. To conclude, the North Atlantic accounts for $23 \%$ of the global marine sequestration of anthropogenic $\mathrm{CO}_{2}$ (Sanders et al. this issue), while providing habitat supporting some of the largest exploited fish stocks on the planet (Trenkel et al. this issue). Clearly the justification for focusing national and international expertise and funding to develop the management capacities necessary to maintain the services this system provides is critical not only for nations bordering the Atlantic but given its critical role in global climate and the earth system.

\section{Acknowledgements.}

We would like to thank all the co-authors of the special issue articles for their input to this synthesis issue as well as the participants of the US Canadian EU planning workshop held in Arlington,14-16 April 2014 where discussion led to a collaborative international research program on the coupled North Atlantic Arctic System. Support for the activities of the first author was made available from the EC $7^{\text {th }}$ Framework programme, EURO-BASIN Integrated Project on Basin-Scale Analysis, Synthesis and INtegration is funded by Framework Programme 7 (Contract 264933).

\section{References:}

Alheit, J., Mollmann, C., Dutz, J., Komilovs, G., Loewe, P., Mohrholz, V., Wasmund, N., 2005. Synchronous ecological regime shifts in the central Baltic and the North Sea in the late 1980s. ICES Journal of Marine Science 62, 1205-1215.

Allen, J.I., Polimene, L., 2011. Linking physiology to ecology: towards a new generation of plankton models. Journal of Plankton Research 33, 989-997. 
Anderson, T.A., Mitra, A., 2010. Dysfunctionality in ecosystem models: an underrated pitfall? Progress in Oceanography 84: 66-68.

Arnason, R., Kelleher, K., Willman, R., 2009. The Sunken Billions: The economic justification for fisheries reform. Agriculture and rural development (p. 100): The World Bank and Food and Agriculture Organization.

Bianchi, D., Galbraith, E. D., Carozza, D. A., Mislan, K. \& Stock, C. A., 2013. Intensification of open-ocean oxygen depletion by vertically migrating animals. Nature Geosciences 6, 545-54.

Buesseler, K. O., Boyd, P.W., 2009. Shedding light on processes that control particle export and flux attenuation in the twilight zone of the open ocean. Limnology and Oceanography 54,1210-1232.

Cripps, G., Lindeque, P., Flynn, K.J., 2014. Have we been underestimating the effects of ocean acidification in zooplankton? Global Change Biology. doi: 10.1111/gcb.12582.

Doney, S.C., Balch, W.M., Fabry, V.J., Feely, R.A., 2009. Ocean acidification: A critical emerging problem for the ocean sciences. Oceanography 22,16-25,

http://dx.doi.org/10.5670/oceanog.2009.93.

Ducklow, H.W., Steinberg, D.K., Buesseler, K.O., 2001. Upper ocean carbon export and the biological pump. Oceanography 14(4). 50-58, http://dx.doi.org/10.5670/oceanog.2001.06

Flynn, K.J., Stoecker, D.K., Mitra, A., Raven, J.A., Glibert, P.M., Hansen, P.J., Granéli, E., Burkholder, J.A. 2013. Misuse of the phytoplankton-zooplankton dichotomy: the need to assign organisms as mixotrophs within plankton functional types. Journal of Plankton Research 35, 311.

Giering, S.L.C., Sanders, R., Lampitt, R.S., Anderson, T.R., Tamburini, C., Boutrif, M., Zubkov, M.V., Marsay, C.M., Henson, S.A., Saw, K., Cook, K., Mayor, D.J., (2014) Reconciliation of

Holt, J., Allen, J.I., Anderson, T.R., Brewin, R., Butenschon, M., Harle, J., Huse G., Lehodey, P., Lindemann, C., Memery, L., Baris Salihoglu, B., Senina, I., Yool, A., 2014. Challenges in integrative approaches to modelling the marine ecosystems of the North Atlantic: Physics to Fish and Coasts to Ocean. Progress in Oceanography, This issue.

Houde, E. D., 2008. Emerging from Hjort's Shadow. Journal of Northwest. Atlantic Fisheries Science 41: 53-70. doi:10.2960/J.v41.m634

IPPC Climate Change 2007: Synthesis Report Contribution of Working Groups I, II and III to the Fourth Assessment Report of the Intergovernmental Panel on Climate Change Core Writing Team, Pachauri, R.K. and Reisinger, A. (Eds.) IPCC, Geneva, Switzerland. Pp. 104

Kiørboe, T., 2000. Colonization of marine snow aggregates by invertebrate zooplankton: Abundance, scaling, and possible role. Limnology and Oceanography 45, 479-484.

Koski, M., Kiørboe T., Takahashi, K., 2005. Benthic life in the pelagic: Aggregate encounter and degradation rates by pelagic harpacticoid copepods Limnology and Oceanography 50, 12541263. 
Lignell, R., Heiskanen, A.-S., Kuosa, H., Gundersen, K., Kuuppo- Leinikki, P., Pajuniemi, R., Uitto, A., 1993. Fate of a phytoplankton spring bloom: sedimentation and carbon flow in the planktonic food web in the northern Baltic. Marine Ecology Progress Series 94, 239-252.

Merino, G., Barange, M., Fernande, J.A., Mullon C., Cheung W., Trenkel, V., Vicky Lam, V., 2014. Estimating the economic loss of North Atlantic fisheries. Progress in Oceanography. This issue.

Mitra, A., Davis, C., 2010. Defining the "to" in end-to-end models. Progress in Oceanography 84, $39-42$.

Mitra, A., Castellani, C., Gentleman, W., Jónasdóttir, S.H., Flynn K.J., Bode, A., Halsband, C., Kuhn, P., Licandro, P., Agersted, M.D., Calbet, A., Lindeque, P., Koppelmann, R., Møller, E.F., Gislason, A,, Nielsen, T.G., St. John M. A., 2014. Bridging the gap between marine biogeochemical \& fisheries sciences; configuring zooplankton link. Progress in . Oceanography

Mitra, A., Flynn, K.J., Burkholder, J.M., Berge, T., Calbet, A., Raven, J.A., Granéli, E., Glibert, P.M., Hansen, P.J., Stoecker, D.K., Thingstad, F., Tillmann, U., Våge, S., Wilken, S., Zubkov, M.V., 2014. The role of mixotrophic protists in the biological carbon pump. Biogeosciences, $11,995-1005$.

Melle, W., Runge, J.A., Head, E., Plourde, S., Castellani, C., Licandro, P., Pierson, J., Jonasdottir, S.H., Johnson, C., Broms, C., Debes, H., Falkenhaug, T., Gaard, E., Gislason, A., Heath, M.R., Niehoff, B., Nielsen, T.G., Pepin, P., Stenevik, E.K., Chust, G. (this issue). The North Atlantic Ocean as habitat for Calanus finmarchicus: environmental factors and life history traits. Progress in Oceanography. http://dx.doi.org/10.1016/j.pocean.2014.04.026

Morales, C.E., Bedo, A., Harris, R.P., Tranter P.R.G., 1991. Grazing of copepod assemblages in the north-east Atlantic: the importance of the small size fraction. Journal of Plankton Research 13, 455-472.

Orr, J.C., Fabry, V.J., Aumont, O., Bopp, L., Doney, S.C., Feely, R.A., Gnanadesikan, A., Gruber, N., Ishida, A., Joos, F., Key, R.M., Lindsay, K., Maier-Reimer, E., Matear, R., Monfray, P., Mouchet, A., Najjar, R.G., Plattner, G.K., Rodgers, K.B, Sabine, C.L., Sarmiento, J.L., Schlitzer, R., Slater, R.D., Totterdell, I.J., Weirig, M.F., Yamanaka, Y., Yool, A., 2005, 'Anthropogenic ocean acidification over the twenty-first century and its impact on calcifying organisms' Nature, 437, 681-686.

http://www.nature.com/nature/journal/v437/n7059/full/nature04095.html\#B2

Palacz, A.P., St. John, M.A., Brewin, R., Hirata T., Gregg W.W., 2013. Distribution of phytoplankton functional types in high-nitrate, low-chlorophyll waters in a new diagnostic ecological indicator model. Biogeosciences, 10:7553-7574 DOI: doi:10.5194/bg-10-75532013.

Poulton, A.J., Charalampopoulou, A., Young, J.R., Tarran, G.A., Lucas, M.I., Quartlya G.D., 2010. Coccolithophore dynamics in non-bloom conditions during late summer in the central Iceland Basin (July-August 2007) Limnology and Oceanography, 55,1601-1613. 
Rost, B., Zondervan, I., Wolf-Gladrow D., 2008. Sensitivity of phytoplankton to future changes in carbonate chemistry: current knowledge, contradictions and research directions. Marine. Ecology Progress Series. 373, 227-237

Sanders, R., Henson, S., Koski, M., De La Rocha, C., Painter, S, C., Poulton, A., Riley, J., Salihoglu, B., Visser, A., Yool, A., Bellerby, R.,Martin A., 2014. The Biological Carbon Pump in the North Atlantic. Progress in Oceanography, This issue

Scheffer, M., Bascompte, J., Brock, W.A., Brovkin, V., Carpenter, S.R., Dakos, V., Held, H., H. van Nes, E., Rietkerk M., Sugihara G., 2009. Early-warning signals for critical transitions. Nature 461, 53-58. doi:10.1038.

Trenkel,V.M., Huse, G., MacKenzie, B., Alvarez, P., Arrizabalaga, H., Castonguay, M., Goñi, N., Grégoire, F., Hátún, H., Jansen, T., Jacobsen, J.A., Lehodey, P., Lutcavage, M., Mariani, P., Melvin, G., Neilson, J.D., Nøttestad, L., Óskarsson, G.J., Payne, M., Richardson, D., Senina, I., Speirs, D.C., 2014. Comparative ecology of widely-distributed pelagic fish species in the North Atlantic: implications for modelling climate and fisheries impacts. This issue

Thomalla, S.J., Poulton, A.J., Sanders, R., Turnewitsch, R., Holligan, P.M., Lucas,M.I., 2008. Variable export fluxes and efficiencies for calcite, opal and organic carbon in the Atlantic Ocean: A ballast effect in action? Global Biogechemical Cycles, 22, doi:10.1029/2007GB002982.

Turner, J.T., 2002. Zooplankton faecal pellets, marine snow and sinking phytoplankton blooms. Aquatic Microbial Ecology, 27 57-102, DOI:10.3354/ame027057.

Vichi, M., Pinardi, N., Masina, S., 2007a. A generalized model of pelagic biogeochemistry for the global ocean ecosystem. Part I: Theory. Journal of Marine Systems. 64, 89-109.

Vichi, M., Masina, S., Navarra, A. 2007b. A generalized model of pelagic biogeochemistry for the global ocean ecosystem. Part II: Numerical Simulations. Journal of Marine Systems. 64, 110134.

Wassmann, P., 1998. Retention versus export food chains processes controlling sinking loss from marine pelagic systems, Hydrobiologia, 363, 29-57.

Wassmann, P., Bauernfeind, E., Fortier, E., Fukuchi, B., Hargrave, B., Moran, B.,Noji, T., Nöthig, E. M., Peinert, R., Sasaki, H., and Shevchenko, V. P., 2003. Particulate organic carbon flux to the sea floor, in The Organic Carbon Cycle in the Artic Ocean, edited by R., Stein and MacDonald, R.M., pp. 101-138 Springer Verlag Heidelberg-Berlin-New York.

Wiebe, P.H., Harris, R.P., St. John, M.A., Werner, F.E., de Young B., Pepin P., (Eds.). 2009. BASIN: Basin-scale Analysis, Synthesis, and INtegration. Science Plan and Implementation Strategy. GLOBEC Report 27: 43pp. 